\title{
An Exploratory Study in Using Music Videos among Pre-service Teachers: Sing Along with Economics Concepts
}

\author{
Khoo Yin Yin ${ }^{1, *}$, Noor Aini Ahmad ${ }^{1}$, Zainizam Zakariya ${ }^{1}$, Azila Abdul Razak ${ }^{1}$, Stanley Yap Peng Lok ${ }^{2}$ \\ ${ }^{1}$ Sultan Idris Education University, Malaysia \\ ${ }^{2}$ SEGi University, Malaysia
}

Copyright $\bigcirc 2019$ by authors, all rights reserved. Authors agree that this article remains permanently open access under the terms of the Creative Commons Attribution License 4.0 International License

\begin{abstract}
Education 4.0 has emphasised on the integration of information and communication technology (ICT) in education. Enhancing the creative and innovative thinking among pre-service teachers has become one of the important elements in Education 4.0. Most of the art students, who take Form Four economics in secondary schools, generally face difficulties in mastering economic concepts. In order to make the lessons more interesting and easy to remember, the economics teachers should develop some innovative teaching and learning methods to attract students' attention. This study aimed to examine pre-service teachers' learning interest. This study also further examined the understanding of economics concepts. Learning with songs can make learning activities more interesting for the class, especially with music videos. This study employed the survey as research method. A total of 50 pre-service teachers were employed randomly as samples. From the findings, music videos can enhance learning interest among pre-service teachers. In addition, the data also indicated a positive result for students' understanding with music videos. Future study will focus on video making combined with augmented reality.
\end{abstract}

Keywords Economics, Songs, Music Videos, Economics Concepts, Pre-service Teachers

\section{Introduction}

Education 4.0 has emphasised on the integration of information and communication technology (ICT) in education. Learning in the digital world, students are expected to become independent and get most of the information from digital sources. It is a known fact that most students are tech-savvy. However, do they have the innovative and creative thinking when utilising all the modern technologies? In other words, students must be able to develop or design something from their learning experiences. Since creative and innovative students are the need of Education 4.0 (Puncreobutr, 2016), teachers should get ready to develop the learning opportunity for the students. Most educators in the new learning era post assignment online and form students into groups to solve problems (Anggraeni, 2018). These methods are only transforming the learning platform, but lack emphasising on creative and innovative thinking. Are our educators ready for Education 4.0, especially our pre-service teachers? Enhancing the creative and innovative thinking among students has become one of the important elements in Education 4.0. Even though all the students are digital natives, however, it is important to develop students' 21 st century thinking skills towards the capability of creating new things from new knowledge (Thapanee, 2017). If our pre-service teachers do not have the relevant skills, they won't be competent to develop the creative and innovative skills among students.

Economics is always classified as a dry and difficult subject in secondary school. Most of the art students who take Form Four economics in secondary schools generally face difficulties in mastering economic concepts (Khoo \& Fitzgerald, 2017). Furthermore, most of the art students in Malaysia upper secondary schools are those students who did not perform well in their lower secondary assessments. In order to make the lesson more interesting and easy to remember, the economics teachers should develop some innovative teaching and learning methods to attract students' attention. In an attempt to make the economics lesson more fun and memorable, researchers have tried many methods. A few researchers have tried to use music. However, the power of music is yet to be examined, especially in economics courses. This is the gap in the literature related to music video. The integration of economics concepts and songs into video builds bridges 
between students and the economics concepts. The purpose of this study was examined the pre-service teachers' learning interest. This study also further examined the understanding of economics concepts using music videos.

\section{Literature Review}

\section{Learning with Songs}

Learning with songs can make the learning activities more interesting for the class. Songs which were unfamiliar to the students were employed as listening texts with questions and answers (Phuong, 2014; Naveen, Mohamad Arif, Yong, Vishroathi, Swany \& Ashwini, 2016). However, Phuong (2014) also stated that the lesson would be more successful if familiar songs were used, which included popular songs available on YouTube and video clips. The lyrics of songs are used to attract students' interest in economics. Musical selections contain lyrics that are related with economics concepts, for example, money, spending and saving, employment, recession, occupational choices and other topics (Tinari \& Khandka, 2000; Krasnozhon \& Leonid, 2013). The findings of Rousu and Conrad (2017) showed significant results on how the "Hamilton" song made the students think like economist in the principle of economics lesson. They said that song allows lecturers to connect more to students, it also enhances students' learning interests via music, and shows them how economics is applicable outside the classroom setting. Another researcher (McClough \& Heinfeldt, 2012) also agreed that the use of music to convey economics concepts in macroeconomics courses can make the students learn the economics concepts effectively, especially when music integrated with technology (Mito \& Bauer, 2017).

\section{Learning with Music Video}

The use of media to enhance teaching and learning complements traditional approaches of learning. The proper media such as videos can create a meaningful lesson, especially music videos. Music videos are short videos that accompany a song (Hutchinson \& Ieva, 2009). Music videos may consist of a combination of lyrics, music, music instrumental and a dramatic depiction of the song being performed (Fraser, 2005; Ohrt, Foster, Hutchinson \& Ieva, 2009).

Music videos are an excellent teaching and learning tool for getting students' attention and exploring broad issues (McClain, 2016). Researchers stated that students developed music videos in order to learn technology skills and music (Cayari 2014; Nasrifan \& Saidon, 2019). In fact, students can enhance their creativity and innovative skills too. Some studies indicate that through music videos, the students have become more engaged in learning activities, and remember the concepts easily (Crowther, McFadden, Fleming \& Davis, 2016).

\section{Conceptual Framework}

This framework was developed by researchers based on Vygotsky (1978) of the proximal development zone (ZPP). According to the framework, ZPP is at the center of the real ability that can achieved by the students.

At this level, students create their knowledge through own learning. However, all the learning of the students are influenced by existing knowledge or past experience. In order to create existing knowledge and maximize the student's true potential, music video that related to students daily life and economics concepts were created.

According to Vygotsky (1978), ZPP is a level of ability that an individual can achieve with the assistance of teaching aids or peers. With the music video, students can optimize their existing skills. Therefore, based on this study, students in the ZPP have a good chance of maximizing their ability and understanding of the content at the optimum level. Music video is regarded as a support medium to assist students in mastering content for Economics subjects.

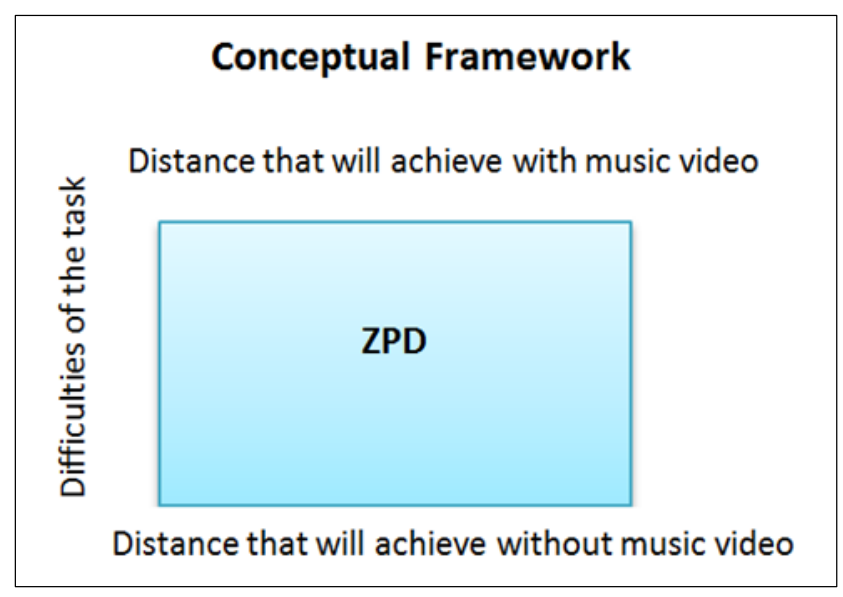

Figure 1. Conceptual Framework

\section{Methodology}

This study employed the survey as research method. A total of 50 pre-service teachers were employed randomly as samples. All the participants had gone through 2 sessions of video making. When they possessed the relevant skills of video making, the instructor showed them some examples of the music videos that consisted of song and economics concepts. Each of them had to select a different subtopic to develop the video. They were allocated two weeks for the first phase. All the pre-service teachers had to present their ideas, in term of which song or economics concepts that were selected. The instructor provided some suggestions to assist the pre-service teachers to develop 
quality videos. However, all of them had to develop their own lyrics. They were encouraged to compose their own song if possible. Otherwise, they were allowed to use the existing songs, but adapted with their own lyrics. All the lyrics must be related to the economics concepts.

In phase two, the pre-service teachers presented their completed music video. The instructor and peers provided the presenter some constructive comments. Meanwhile, the other pre-services teachers also explored their peers' videos. After this phase, all the participants had to complete a 20-item, five point Likert scale questionnaire.
The questionnaire was employed to measure the pre-service teachers' learning interest after implementing music video. The questionnaire was designed using the format of: 5-Strongly agree, 4- Agree, 3- Neutral, 2Disagree and 1-strongly disagree. Content and face validity had been examined to ensure a set of systematic assessments was employed in this study. The instrument has a reliability of Cronbach's Alpha .901 . The result of Cronbach's Alpha is reliable, because it is higher than .70 (Sekeran \& Bougie, 2010). Table 1 illustrated the finding of Cronbach's Alpha.

Table 1. The Finding of Cronbach Alpha

\begin{tabular}{|c|c|c|c|c|}
\hline Item & $\begin{array}{c}\text { Scale mean if item } \\
\text { deleted }\end{array}$ & $\begin{array}{c}\text { Scale Variance if Item } \\
\text { Deleted }\end{array}$ & $\begin{array}{l}\text { Corrected Item-Total } \\
\text { Correlation }\end{array}$ & $\begin{array}{c}\text { Cronbach's Alpha if Item } \\
\text { Deleted }\end{array}$ \\
\hline 1 & 79.80 & 51.184 & .421 & .901 \\
\hline 2 & 79.92 & 50.647 & .698 & .891 \\
\hline 3 & 79.54 & 52.049 & .645 & .893 \\
\hline 4 & 79.64 & 52.072 & .603 & .894 \\
\hline 5 & 79.96 & 50.692 & .589 & .894 \\
\hline 6 & 79.72 & 52.491 & .531 & .896 \\
\hline 7 & 79.74 & 51.829 & .720 & .892 \\
\hline 8 & 79.60 & 52.490 & .639 & .894 \\
\hline 9 & 79.72 & 53.389 & .455 & .898 \\
\hline 10 & 79.70 & 51.112 & .694 & .892 \\
\hline 11 & 79.66 & 50.760 & .649 & .892 \\
\hline 12 & 79.86 & 49.388 & .731 & .890 \\
\hline 13 & 82.50 & 59.969 & -.248 & .923 \\
\hline 14 & 80.04 & 51.713 & .461 & .898 \\
\hline 15 & 79.82 & 50.722 & .635 & .893 \\
\hline 16 & 79.58 & 52.289 & .613 & .894 \\
\hline 17 & 79.70 & 51.235 & .604 & .894 \\
\hline 18 & 79.62 & 52.322 & .666 & .893 \\
\hline 19 & 79.62 & 52.322 & .532 & .896 \\
\hline 20 & 79.40 & 52.898 & .615 & .895 \\
\hline
\end{tabular}




\section{Findings}

The respond rate to the questionnaire was $98.03 \%$. Overall only one respondent did not answer the questionnaire. The analysis of the data showed that the students' mean scores ranged from 4.66-1.58 with the average mean of 4.20 . The questionnaire aimed to examine the pre-service teachers' learning interest after they produced their own music videos. The majority of the respondents had answered 'strongly agree' and 'agree' in most of the items, except the negative item 'I will not watch music video again'. This item stated the lowest mean score (1.58). However, 'I like music videos very much' scored the highest mean (4.66) as compared to other items.

Two main key findings in this study were: The pre-service teachers enjoyed learning with music videos; and the music video's learning method was more effective than other methods. The findings of frequency and percentage showed that $40.6 \%$ students selected 'strongly agree' of the item and $47.4 \%$ selected 'agree'. The other two statements shared the next highest score, 'I found the lesson taught using music videos enjoyable' and 'learning materials in the videos were colorful, animated and interesting'. These items showed the mean scores of 4.52 and 4.48 respectively. In term of understanding of economics concepts, this data also showed a positive result with the average mean score of 4.23. The item 'I can understand economics concepts better with music videos' indicated 4.30 mean score and 'I remember key words easily when learning with music videos' showed 4.33 mean score. The overall report is illustrated in Figure 2.

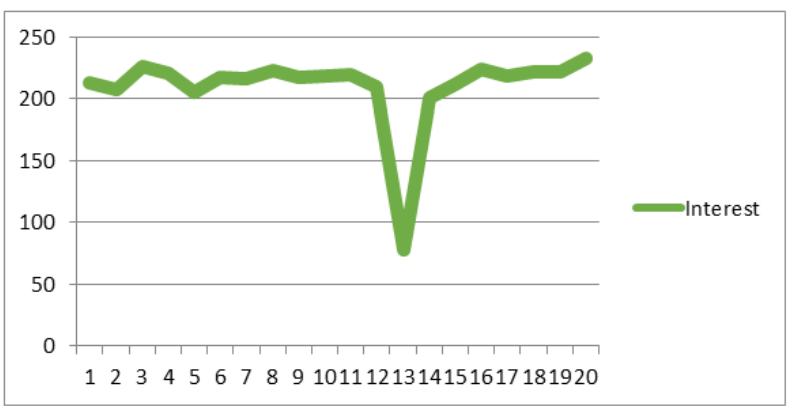

Figure 2. Overall results of Students' Interest

\section{Discussion}

The findings explore the use of music videos that are related to economics concepts in teaching economics course. Prior studies showed that a meaningful teaching can happen outside the classroom with the use of songs (Maryam, Hesamoddin \& Azar Hosseini, 2016). Economics content music is a novel way for pre-service teachers to learn, it helps them to memorize the concepts, the fact and the core theories easily. Learning is fun when the students sing along with the music videos, and as a result they could master the concepts, key words, and phrases. The pre-service teachers learned without pressure and they did not feel bored with the dry subject. Lessons would become meaningful with their participation (Governor, Hall \& Jackson, 2013). However, how the lesson was conducted is always the key factor to enhance pre-service teachers' learning outcome rather than the fun they gained from the song (Raehsler, 2013). The use of songs in the learning process may bring the pre-service teachers closer to the lecturers (Ferrarese \& Shaik Abdul Malik, 2013). Moreover, all the pre-services teachers have gained the hand-on experience during video making. They may use this knowledge when they serve as teachers in the future.

\section{Conclusions}

The present study contributes to the body of knowledge and research on teaching and learning economics by adding an insight on the possibility for policy makers, educators and curriculum developers to the use of music videos during lessons. This teaching method not only can attract per-service teachers' attention, but also enhance their learning interest. This learning method is also in line with the 21 st century teaching method. Despite the strength of the significant results of this study, it has its limitations due to the sample size is small. Future study will continue to focus on video making combined with augmented reality.

\section{Acknowledgements}

This research is funded by UPSI Innovative Teaching and Learning Research Grant (2018-0174-107-01).

\section{REFERENCES}

[1] Anggraeni, C. W. (2018). Promoting education 4.0 in English for survival class: What are the challenges? Metathesis, 2 (1), 12-24.

[2] Cayari, C. (2014). Using informal education through music video creation. General Music Today. 27(3), 17-22.

[3] Crowther, G. J., McFadden, T. , Fleming, J. S., \& Davis, K. (2016). Leveraging the power of music to improve science education. International Journal of Science Education, 38(1), 73-95.

[4] Ferrarese, M.1., \& Shaik Abdul Malik Mohamed Ismail. (2013). A perspective on alternative music scene involvement and English language learning. Pertanika Journal Social Science \& Humanities, 21 (3): 881 - 896 (2013).

[5] Fraser, P. (2005). Teaching music videos. London: BFI.

[6] Governor, D., Hall, D., \& Jackson, D. (2013). Teaching and learning science through song: Exploring the experiences of 
students and teachers. International Journal of Science Education, 35(18), 3117-3140.

[7] Khoo, Y. Y., \& Fitzgerald, R. (2017). Peer learning with concept cartoons enhance critical thinking and performance in secondary school economics. Journal of Economics and Economic Education Research, 18(1), 1-13.

[8] Krasnozhon, L. A. (2013). Using popular music to teach principles of economics: Beyoncé's take on demand and quantity demanded. The Journal of Private Enterprise, 28(2): 139-149.

[9] Naveen, K., Mohamad Arif, W., Yong, T. C., Vishroathi, Swany, R. S. \& Ashwini, A. P. (2016). The effect of Listening to music on concentration and academic performance of the student: Cross-sectional study and Medical undergraduate students. Research Journal of Pharmaceutical Biological and Chemical Sciences, $1190-1195$

[10] Maryam, A., Hesamoddin, S., \& Azar Hosseini, F. (2016): The value of song lyrics for teaching and learning English phrasal verbs: A corpus investigation of four music genres. Innovation in Language Learning and Teaching, 1-13.

[11] McClain, J. M. (2016). A framework for using popular music videos to teach media literacy. Dialogue: The Interdisciplinary Journal of Popular Culture and Pedagogy. $3(1)$. http://journaldialogue.org/issues/a-framework-for-using-po pular-music-videos-to-teach-media-literacy/

[12] McClough, D., \& Heinfeldt, J. (2012). Assessing the effectiveness of music lyrics in conveying economic concepts. Journal of Economics and Economic Education Research, 13(2), 55-65.

[13] Mito, H. \& Bauer, W. (2017). ICT in music education. Routledge.

[14] Nasrifan, M.N. H. \& Saidon, Z.L. H. (2019). Designing online interactive application of learning music theory in blended learning mode. International Journal of Recent Technology and Engineering, 7(6), 226-233.

[15] Ohrt, J. H., Foster, J. M., Hutchinson, T. S., \& Ieva, K. P. (2009). Using music videos to enhance empathy in counsellors-in-training. Journal of Creativity in Mental Health., 4, 320-333.

[16] Phuong, T. A. L. (2014). Diversifying the input and the outcome: A case study. Pertanika Journal Social Science \& Humanities, 22 (1), 85 - 93.

[17] Puncreobutr, D. (2016). Education 4.0: New challenge of learning. St. Theresa Journal of Humanities and Social Sciences, 2(2), 92-97.

[18] Raehsler, R.D. (2013). 'The use of popular music to teach introductory economics in a live and online environment', Int. J. Pluralism and Economics Education, Vol. 4, No. 1, pp.78-92.

[19] Rousu, M. C., \& Conrad, C. A. (2017). Economic lessons from the Musical Hamilton. Journal of Economics Teaching, $31-50$.

[20] Sekeran, U., \& Bougie, R. (2010). Research methods for business: A skill building approach (5th ed). Chichester: John Willey \& Sons Ltd.
[21] Tinari, F. D., \& Khandka, K. (2000). From rhythm and blue to broadways: Using music to teach economics. The Journal of Economics Education, 31(3), 253-270.

[22] Thapanee, S. (2017). Instructional strategies to support creativity and innovation in education. Journal of Education and Learning, 6(4), 201-208. 